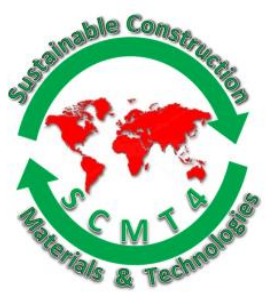

SCMT4

Las Vegas, USA, August 7-11, 2016

\title{
A Comprehensive Approach for Making Sustainable Use of Concrete during Design and Construction
}

\author{
Mohammadsoroush Tafazzoli ${ }^{1}$ \\ ${ }^{1}$ University of Nevada, Las Vegas, Science and Engineering Building (SEB), Room 451. \\ PhD student and Graduate Assistant, LEED AP. Email: 〈tafazzol@unlv.nevada.edu〉.
}

\begin{abstract}
Growing environmental concerns highlight the importance of moving towards more sustainable development. Since construction is one of the main consumers of materials and a huge source of negative environmental impacts, implementing sustainable measures in it, plays a significant role in controlling the impacts of development. Concrete as the most widely used man-made material on the planet, has a remarkable role in making the construction industry more sustainable. Despite the advancements in enhancing concrete over the decades in terms of structural properties and technological aspects, sustainability aspects of the concrete industry have not been improving as much. Considering the increasing demands for concrete and the growing environmental concerns about production and consumption of concrete, vigorous attempts to make the concrete industry more sustainable is a necessity. This review paper is a result of comprehensive study of research findings, policies and recommendations as well as efforts made in making concrete production and consumption more sustainable. Based on this, ten chief recommendations regarding sustainable use of concrete during design and construction phases are provided. Advantages of application, and recommendations for implementation are also provided. Based on this, the paper aims at: 1) increasing awareness about the necessity of implementing sustainable measure in use of concrete by highlighting the significant role of concrete in sustainability and 2) providing an informative handout for professionals of design and construction to get more familiar with some of the most effective policies and solutions regarding sustainable use of concrete.
\end{abstract}

\section{INTRODUCTION}

Concrete is the most widely used construction material in the world. In fact, no man-made material is consumed as much as concrete on the planet. Concrete has also the second rank of consumption of all materials (including natural and man-made materials) after water. The amount of concrete which was consumed in the year of 2002 worldwide is more than half a cubic yard per person (Naik et al. 2005). Figure 1, which is based on the data published by America's Cement Manufacturers, shows portland cement consumption in the U.S. since 1998 and forecasts it until 2020. As it can be seen, it is anticipated that the consumption of cement increases steadily in the upcoming years. These statistics reveal why concrete plays such an indispensable role in the environment. On the other hand, due to hugeness of the concrete market, making changes in policies of the professionals is a challenge.

One serious environmental concern about concrete is the pollution that concrete production causes either directly or indirectly. Production of one ton of portland cement generates one ton of $\mathrm{CO}_{2}$ and a considerable amount of other greenhouse gases (Malhorta, et al. 2004). If we consider the fact that $\mathrm{CO}_{2}$ emissions are 
expected to rise by about $50 \%$ by 2020 (Galloway et al. 1994), then the necessity of taking serious measures to control the pollution which is caused by concrete becomes more clear.

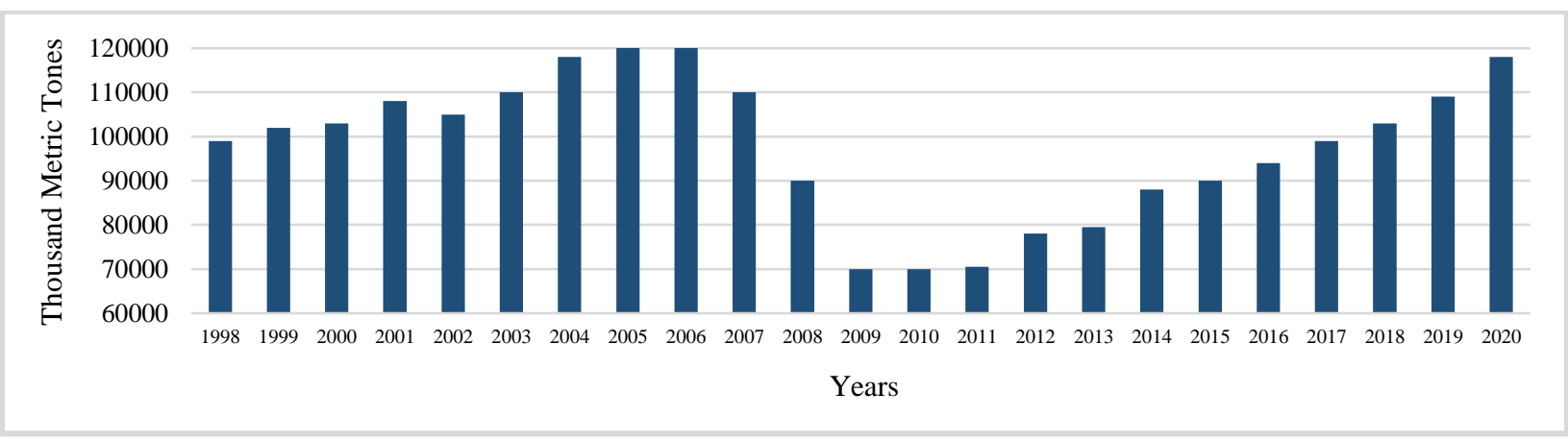

\section{Figure 1. Portland cement consumption in the USA since 1998 and its forecast until 2020}

Another environmental concern which is caused by the tremendous use of concrete, is depletion of some of the materials, which are required for the production of concrete. Supplies of limestone have considerably decreased over the decades for production of concrete (Naik et al. 2005). Extraction of other required aggregates for the production of concrete carries a variety of consequences for the environment.

Additionally, another concern caused by the enormous use of concrete, is the amount of energy it requires for the production of materials. To produce one ton of portland cement, six million BTU is needed (Malhorta et al. 2004 and McKay et al. 2004). In fact, after aluminum and steel, concrete is the third in rank for the most energy extensive processes between all materials (Worrell et al. 2004).

Furthermore, a socioeconomic concern about concrete is the immense employment it generates. In the U.S. concrete-related industries have created around two million jobs in 2002 (United States House Resolution 394, 2004). This means if the concrete industry faces a crisis, millions of people will be affected. This is a reason why the dependence on concrete should be decreased. The sustainability aspects of the concrete industry are shown in Figure 2.

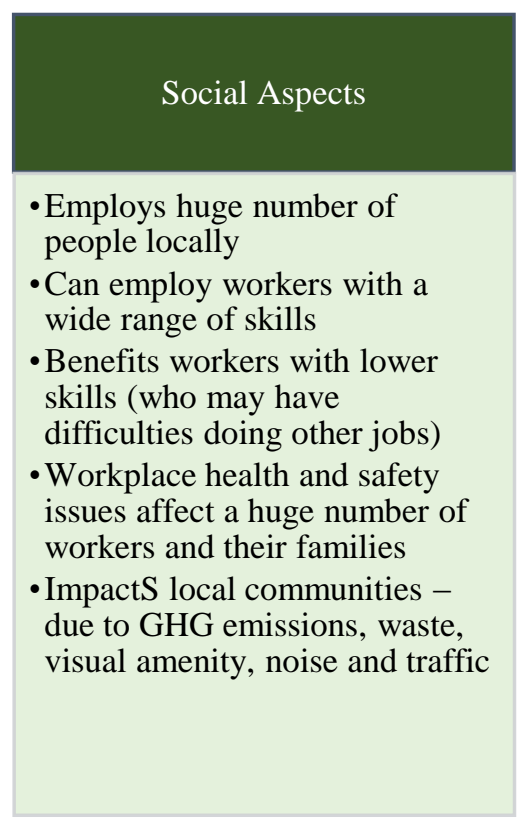

Environmental Aspects
- Uses enormous amount of
electricity
- Uses huge amounts of fuels for
combustion in kilns
- Uses non-renewable resources
as raw materials, including
limestone, shale, clay, sand and
iron
- Uses a wide range of chemicals
and other substances as
admixtures
- Use large amounts of non-
renewable resources for
packaging
- Generates tremendous amount
of non-recyclable waste

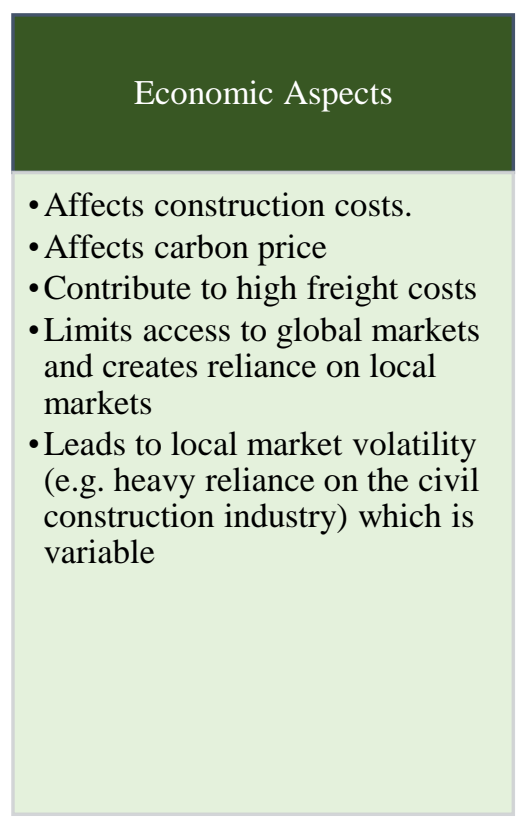

Figure 2. Sustainability aspects of the concrete industry 


\section{BACKGROUND}

In the existing literature, sustainability of concrete is studied in three categories: 1) manufacture of cement, 2) production of concrete, and 3) use of concrete in structures. Figure 3 summarizes some of the main sustainability solutions for each of these three categories.
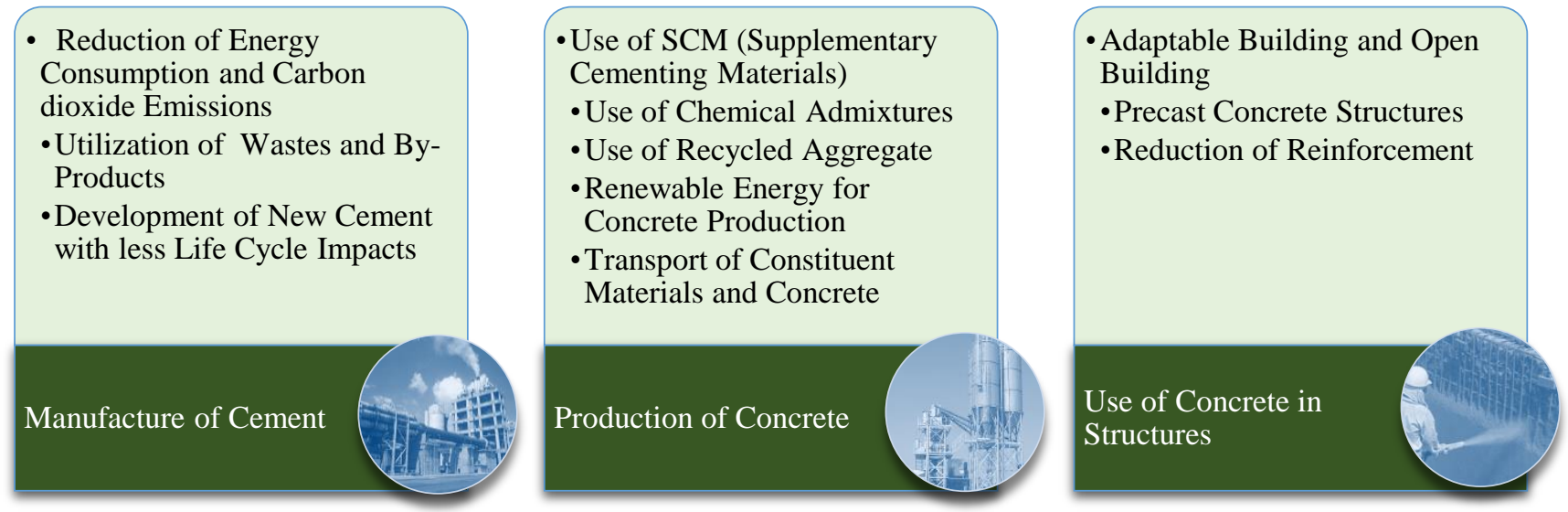

Figure 3. Sustainable solutions for production and consumption of concrete

As McDnoghough et al. (2014) stated, concrete is sustainable if it: 1) requires a very low inherent energy, 2 ) is produced with little waste, 3 ) is made from plentiful resources on earth, 4) produces durable structures, 5) has a very high thermal mass, and 6) is made with recycled materials (Naik et al. 2005).

\section{MOVING TOWARDS SUSTAINABLE USE OF CONCRETE}

It is important to keep in mind that to move towards sustainability, all of the possible short-term and longterm environmental consequences need to be considered in the design. This requires to take the entire lifecycle, including construction, maintenance, demolition, and recycling of buildings into consideration (McDonough et al. 1992 and Worrell et al. 2004). In this part, the suggested approaches for making more sustainable use of concrete during design and the construction phase are presented.

1- Reducing the use of portland cement. One of the fundamental challenges regarding high demands for concrete in the construction industry is providing portland cement. Production of portland cement requires enormous amount of energy which leads to global warming and other environmental consequences (Worrell et al. 2004). It is estimated that the global cement industry contributes around $6 \%$ of all man-made $\mathrm{CO}_{2}$ emissions and is consequently responsible for around $4 \%$ of man-made global warming. (McCaffery et al. 2002).Therefore, the more we try to replace portland cement with other supplementary cementing materials, we will be able to make a significant contribution to control global warming. Plus, this can serve as an effective measure to reduce the extraction of limestone, clay, and silica which are required to produce cement. Some of the advantages of using blended cement are the following:

- reduced GHG emissions (see figure 4 (data from U.S. Concrete ${ }^{\mathrm{TM}}$ website) that shows the changes of $\mathrm{CO}_{2}$ emission when $50 \%$ of portland cement is substituted with slag cement.)

- preserving material resources

- increased productivity of cement

- increased production capacity

- reduced fuel consumption 


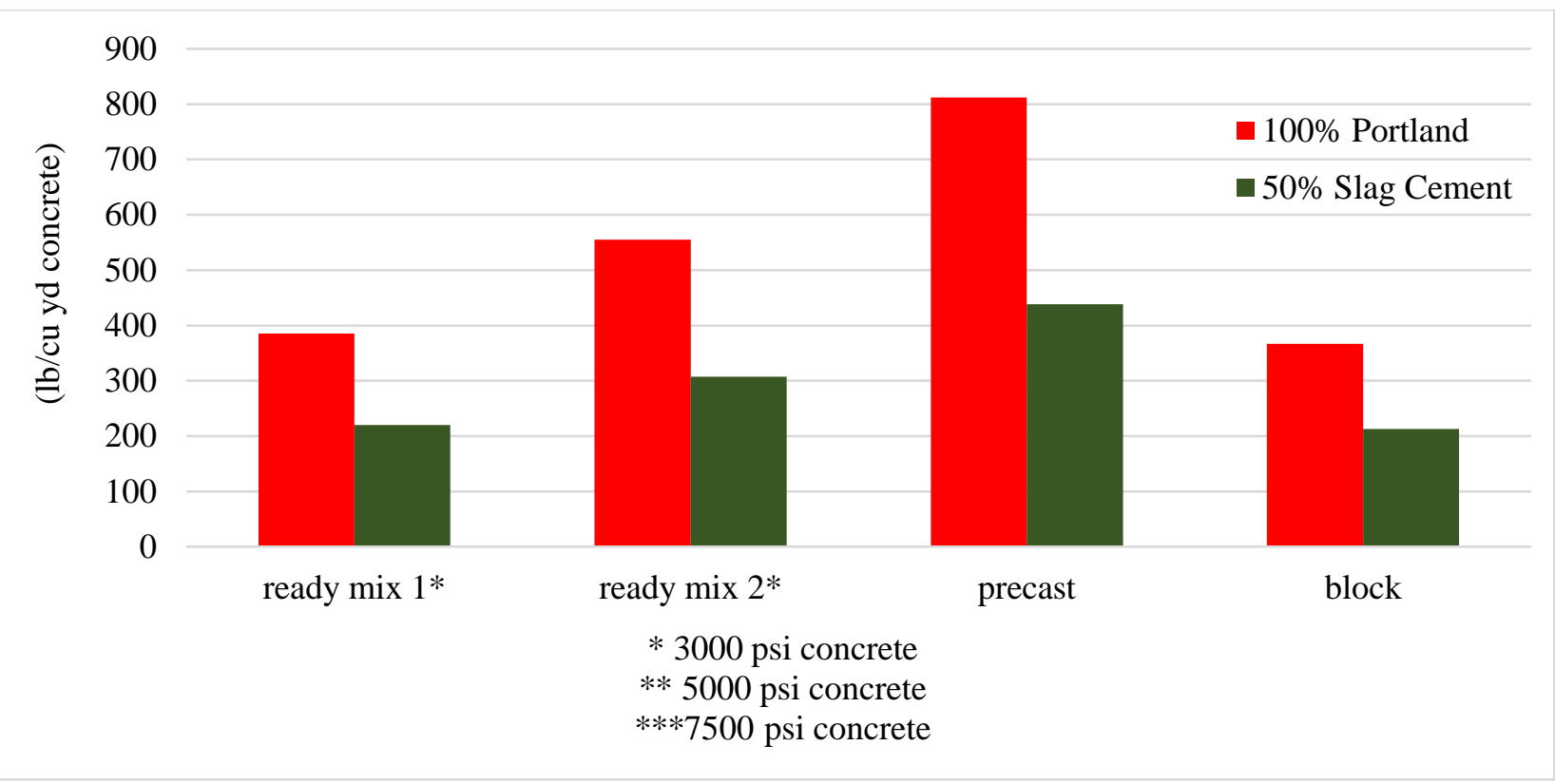

Figure 4. Effect of Slag Cement on embodied greenhouse gas reduction in concrete

Two of the most common replacements for portland cement are mineral admixtures such as fly ash and slag. Pozzolanic materials are commonly the waste products of thermal and steel plants (Malhotra et al. 2014, Naik et al. 2003, and McKay et al. 2004). In addition to the advantages which were mentioned above, using these products assists controlling air pollution which significantly impacts the lives of people.

2- Considering the Choice of Suppliers. To motivate sustainable production of cement, priority should be given to manufacturers who consider the environmental aspects of production. Some of the aspects which are considered to evaluate the life-cycle impacts of a product are: extraction, processing, finish, maintenance, construction, operation, disposal, and recycling.

Although obtaining information about environmentally friendly production may seem difficult, thanks to different standards and labeling that enclose the life cycle information of the products, suppliers who have extracted or sourced their raw materials in a responsible manner can be encouraged. These standards are based on the availability of information for products and materials for the whole life-cycle, and verifying that they have environmentally, economically, and socially preferable life cycle impacts.

Based on this policy, priority of purchase should be given to suppliers who disclose the information about sourcing of their raw materials and ingredients. Also, to decrease the negative impacts of transporting materials, priority should be given to local suppliers. This also promotes local businesses and contributes to social bottom line of sustainability.

3- Utilization of Thermal Mas in Design (Passive Design). Based on statistics, $40 \%$ of national annual energy is solely used for operation of buildings (Cement Association of Canada, 2004). Additionally, buildings are responsible for $70 \%$ of national electricity consumption (EIA 2003). Sustainability requires taking measures to decrease the pressure caused by energy consumption of buildings. To make this happen, one of the most efficient solutions is to take advantage of passive design. By definition, passive design "assigns the heat transfer to natural convection, conduction, and radiation, without using machinery and equipment for the heating processes of collection, conservation, and radiation of sunlight" (Sakai et al. 2012). Concrete is a good choice to take advantage of its thermal mass because concrete has a large thermal capacity and relatively high thermal conductivity. Therefore by taking specific measures in design, concrete can be used as a heat storage insulator. 
Passive design makes it possible to utilize high volumetric heat storage capacity of concrete specifically in external wall systems. Thanks to an ample amount of research regarding this, there are various ways to apply passive design. One significant advantage of passive design regarding concrete is to reduce the amount of cement content in the concrete mix. This can be done by using supplementary cementitious materials. Reducing cementitious content, in turn, leads to many environmental advantages some of which were discussed earlier in this paper.

Concrete's thermal mass can be utilized to flatten daily interior temperature fluctuations. Concrete can keep the indoor temperature low at hot weather by delaying the transfer of heat due to its high thermal mass capacity. The time lag, which is the result of this delay, makes the transferring temperature reduce during the time it needs to penetrate into indoor spaces (damping effect). As a result, concrete's high thermal mass will delay and reduce the impact of outside temperature variations on the indoor temperature. This is shown in figure 5 .

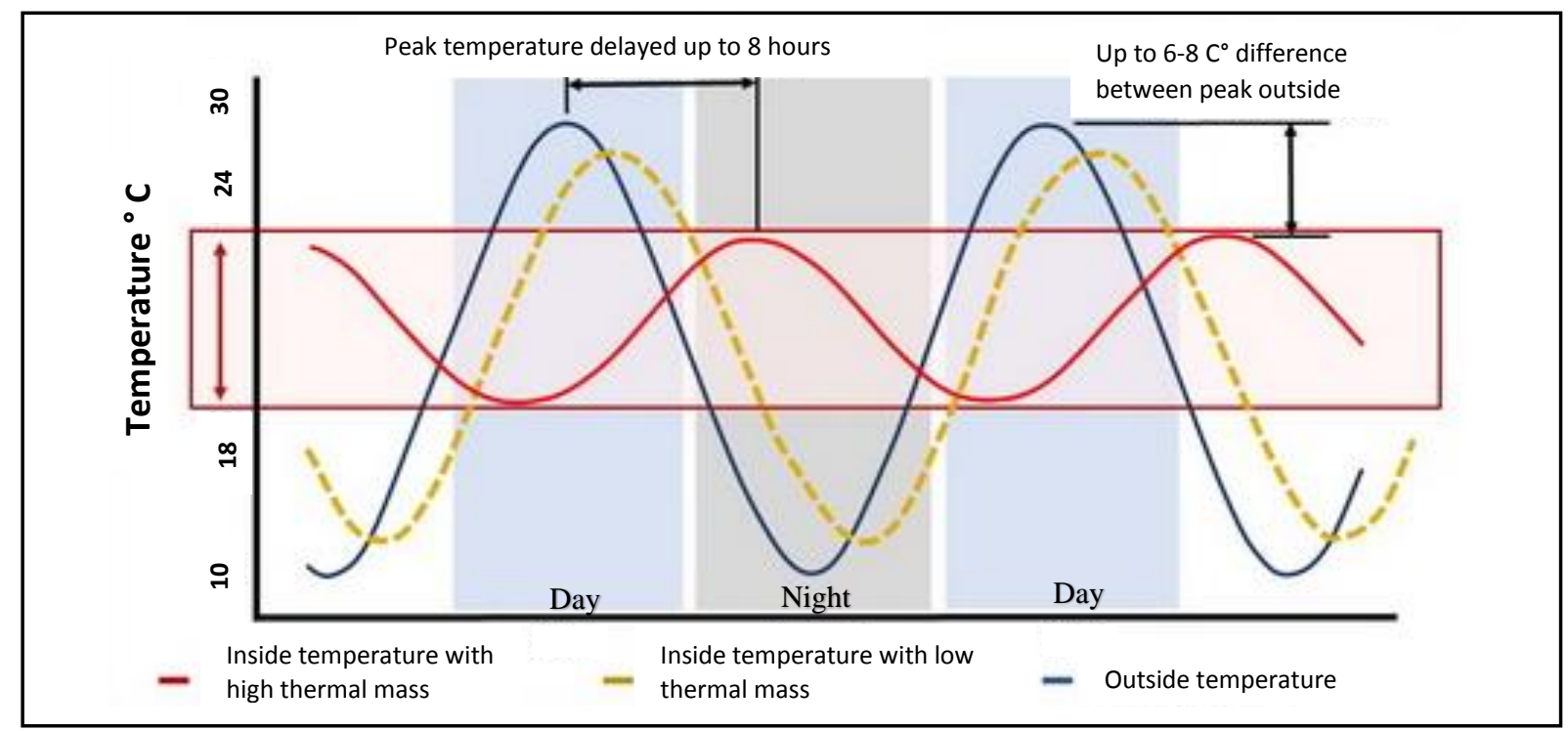

Figure 5. The effect of concrete's high thermal mass on reducing the variations on indoor temperature (Courtesy of National Precast Concrete Association)

4- Using Pervious Concrete Pavements. One significant environmental concern about concrete is its imperviousness which contributes to pollution caused by storm run-offs. To control this, it is required that the surface of concrete pavements have a sufficient porosity that allows the precipitation water to be drained so the runoffs will not contribute to contamination and it will also assist the groundwater recharge to maintain aquifer levels. Making concrete pervious is commonly done by minimizing the use of fine grains in concrete for pavements, parking and sidewalks in particular. Figure 6 shows the detail of a permeable concrete pavement. Below is a list of the advantages of using pervious concrete pavements:

a) Environmental advantages

- Controlling contamination caused by runoffs

- Recharge of underground water

- Channeling water for irrigation and decreasing the water need for irrigation

- Eliminating hydrocarbon pollution from asphalt pavements and sealers

b) Economical advantages

- Lower installation costs

- Permits the use of existing sewer systems

- Increased land utilization

- Lower life-cycle costs 


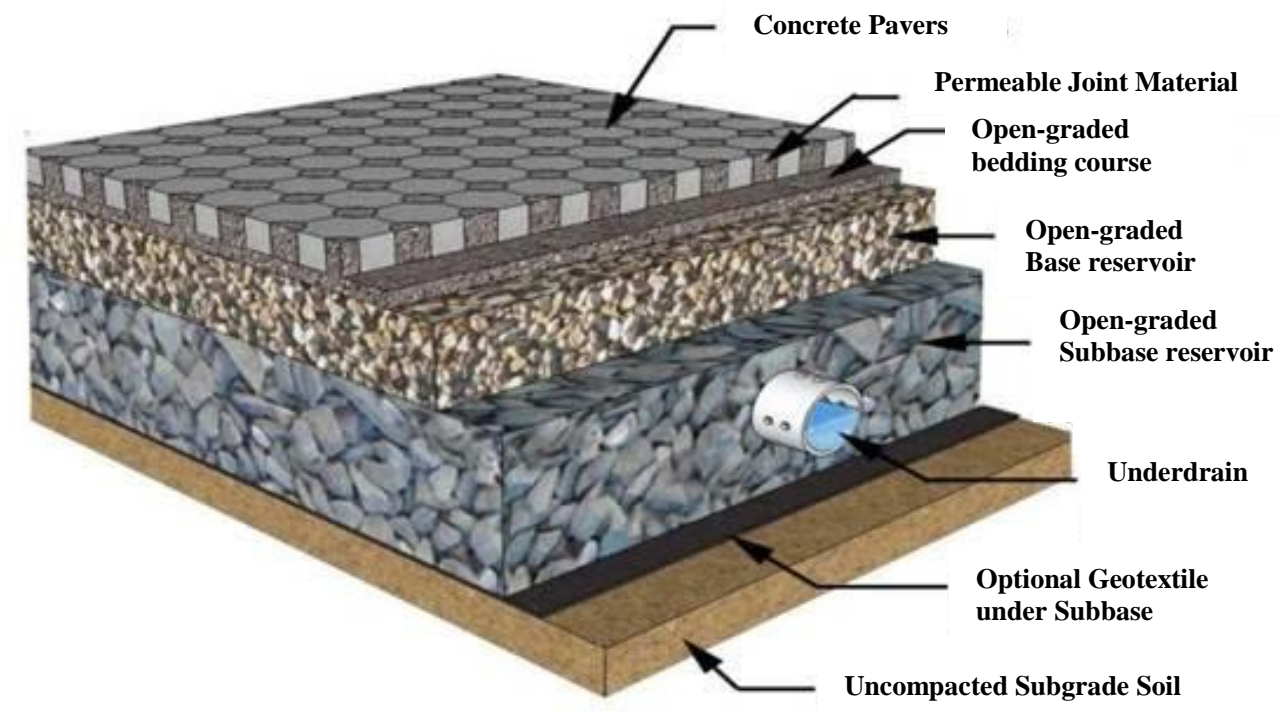

Figure 6. The detail of a permeable concrete pavement (Smith, 2006)

5- Using High Performance Concrete (HPC) Structures. (Ultra) High performance concrete is the result of engineered selection of ingredients to produce a concrete with super resistance and durability. In a more comprehensive view, the following aspects should be considered in producing HPC: 1) structural strength, 2) environmental considerations, 3) construction process, 4) materials and mix design. Table 1, (data form Seminarlinks) shows the materials which are used in HPC and their primary contributions/ desired results:

Table 1. Materials used in HPC and their primary contributions/ desired results

\begin{tabular}{|l|l|}
\hline \multicolumn{1}{|c|}{ Material } & Primary Contributions/ Desired Results \\
\hline Portland cement & Cementing material, Durability \\
\hline Blended Cement & \multirow{2}{*}{$\begin{array}{l}\text { Cementing material } \\
\text { Durability } \\
\text { Fly ash / slag / silica fume }\end{array}$} \\
\cline { 1 - 2 } Calcined clay/ Metakaolin & Flowability \\
\hline Calcined Shale & Reduced water-cement ratio \\
\hline Superplasticizers & Control setting \\
\hline High-range water reducers & Control Setting \\
\hline Hydration control admixtures & Accelerate Setting \\
\hline Retarders & Control Steel Corrosion \\
\hline Accelerators & Reduce cement and water content \\
\hline Corrosion Inhibitors & Reduce shrinkage \\
\hline Water reducers & Control Alkali-silica activity \\
\hline Shrinkage reducer & Improve workability/ reduce paste \\
\hline ASR inhibitors & Durability \\
\hline Optimally graded aggregates &
\end{tabular}

The superior durability is the main reason why high performance concrete is associated with being sustainable. This is because durable materials contribute to resource productivity. This in turn is a solution to meet the increasing demands for concrete in the future. Other advantages of using HPC structures are listed below: 
a) Environmental benifits

- Resistance to harsh elements

- Friendly to the environment

- Adaptable to different requirement

b) Economical benifits

- Minimizes maintenance

- Reduces inspections

- Affords longer lengths

- Extends service life

6- Using Precast Concrete Structures. Precast concrete is aligned with sustainability goals in various ways. Some of the advantages of application of pre-cast concert are the following:

1. Since the water content in precast concrete is lower, it is highly durable and this will assist reduction of demand for extraction of materials in the long run.

2. Since precast concrete is produced under a controlled environment, it generates less waste and increases efficiency of making use of materials. Also, this will decrease the burden of construction waste and debris on the environment.

3. Remote production of precast concrete will considerably reduce indoor air quality for nearby buildings at the job site; noise is also reduced.

4. Production under controlled environment makes it possible for the precast concrete to carry higher structural loads; this will in turn make it possible to have larger spans, optimize cross sections, and eliminate redundant members.

5. Other advantages of production in a controlled environment for the precast concrete is the reduction of weight of concrete panels which leads to the reduction of transportation costs, and reduction of the required energy for erecting panels.

6. Considerable amounts of precast concrete are produced using fly ash, slag, and silica fume which are the by-products that would otherwise go to landfills. Also, reinforcement of precast concrete can be done using recycled steel (Malhorta et al. 2004, Mehta, et al. 2002, Wu et al, 2000). For these reasons, in the designing step of buildings, priority should be given to precast concrete.

7 - Applying Demolition and Construction Waste Management. Considering the huge amounts of concrete consumption, the wastes generated during demolition or construction needs to be controlled to maximize taking advantage of the embodied energy. The chief goal of this control is to decrease the load of disposing concrete-related wastes to landfills. The main policy to make this happen is handling the wastes based on the priority of reducing, reusing, and recycling. To implement it, the following solutions are recommended:

1. Recycle concrete debris to replace it with gravel in concrete production.

2. Use recycled concrete as the base material for roadways. This will reduce the pollution caused by trucking material.

3. Recycle packaging waste (for portland cement).

4. Recycle reinforcement's wastes.

5. Recycle residual aggregates. 
8- Addressing Heat Island Effect. In order to decrease the heat island effect, hard surfaces that are made with concrete (walls, pavements, etc.) should reflect much of the solar radiation. This will control the increase in the temperature of the surrounding environment and assist in decreasing the cooling pressure and energy consumption. Considering the large scope of concrete use in cities, underestimating the importance of controlling the heat island effect will cause the formation of urban heat islands. Concerns about possible consequences of urban heat islands to global warming are rising. Zhao et al. (2011) stated that the urban heat island effect contributes to climate warming by about $30 \%$. This shows the significance of taking measures to control this effect by applying some solutions in the design of concrete surfaces. Some of the recommendations to address the heat island effect are listed below:

1. Use light color concrete pavements

2. By planting trees or architectural design, provide shade over the pavement

3. Keep the wind direction in consideration in design and do the design in a way that wind can more freely blow between the hardscape.

4. Take advantage of planting and vegetation to decrease the cooling load.

5. Use open grid pavement systems

9- Using Green Concrete. There are a number of definitions for "green concrete". In this paper, green concrete is defined as the concrete which is made from concrete wastes that are eco-friendly. To produce green concrete, extra steps are required in the mix design and placement to insure its sustainability and durability. The main purpose of its application is to reduce the environmental impact of concrete. To make this happen, a new approach should be applied in production of concrete which takes all phases of a concrete construction's life cycle such as structural design, specification, manufacturing, and maintenance into consideration. This led to the advent of green concrete. Green concrete was first invented in Denmark in the year 1998 by Dr. WG. Using green concrete has the following advantages:

1. Optimizes use of available materials (increases use of waste products by 20\%)

2. Can be produced locally

3. Better performance

4. Enhanced cohesion workability/ consistency

5. Reduced shrinkage /creep

6. Enhanced durability (it requires less maintenance and repairs)

7. Reduced carbon footprint

8. Enhanced Fire resistance (spalling, heat transfer etc.) (Provis et al. 2007)

Beside all these advantages, green concrete is also not more expensive than conventional concrete. Green concrete can be used in various structures and even heavy constructions such as dames and bridges. Considering the significant benefits of green concrete, designs should be done based on using this whenever possible.

10- Using Insulating Concrete Forms (ICFs.) According to the U.S. Department of Energy's Center for Sustainable Development, buildings consume $40-50 \%$ of the world's total energy, $25 \%$ of its wood harvest, and $16 \%$ of its water. The most effective measure to reduce the consumption of energy, and therefore carbon emissions, is maximizing the energy efficiency of building shell. Unwanted conduction and convection (uncontrolled air leakage) are the main sources of loss of energy in buildings. Thus by applying appropriate shells, the energy consumption of buildings can hugely be reduced. Insulating concrete forms eliminates heat transfer through conduction. Additionally, insulating concrete forms eliminate all spaces in the wall which may lead to air leakage. Having a high density of the concrete, insulating concrete forms can effectively control air leakage.

The mentioned benefits of insulating concrete forms, makes them ideal to be used in: resilient construction in higher-risk areas, exterior walls and building shells, finished basements, buildings pursuing sustainability certificates and /or passive design, green roofs, saferooms, and pools. 


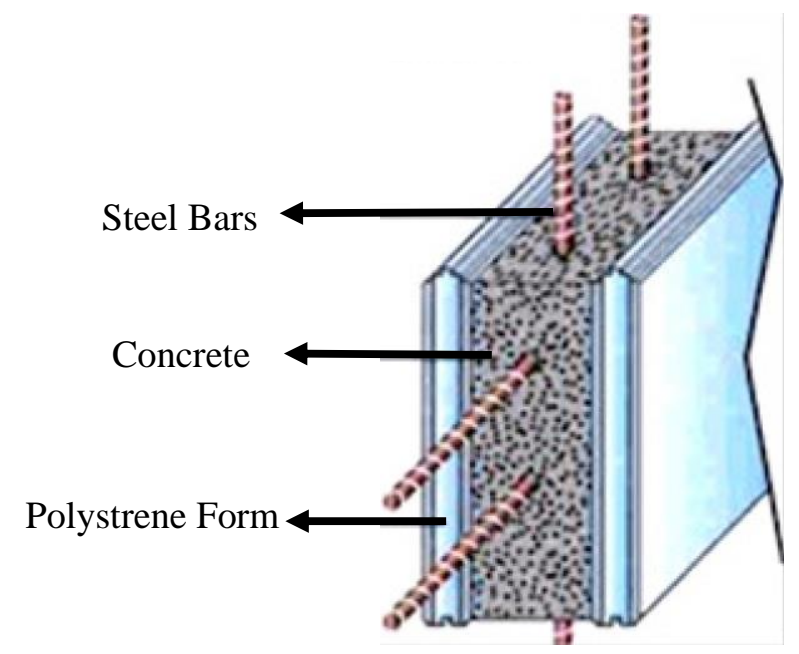

Figure 7. Detail of insulated concrete form

\section{CONCLUSION}

The paper presented ten chief policies to move towards sustainability in concrete industry. Considering the high impacts of the concrete industry on all the three bottom lines of sustainability, effort should be taken to implement these policies. This is only possible if all professionals and authorities first fully understand the importance of taking sustainable measures serious and then it requires a firm determination to be ready to change from what professionals are used to. Sustainability measures regarding concrete should be considered during design to facilitate taking advantage of some of policies like using pre-cast concrete. Additionally, during the construction phase there are numerous ways to implement sustainability measures like recycling concrete. These policies should be pursued at different stages of construction. All these efforts, when accumulated, can have great contributions to make the concrete industry more sustainable.

\section{REFERENCES}

"Concrete Thinking for a Sustainable Future." Cement Association of Canada, http://www.cement.ca/cement.nsf/internetE/28BAAE6AB42AB69C852567B60056B657?opendocume nt, May 2004.

Aitcin, P. C. (2011). High performance concrete. CRC Press.

Duxson, P., Provis, J. L., Lukey, G. C., \& Van Deventer, J. S. (2007). The role of inorganic polymer technology in the development of 'green concrete'. Cement and Concrete Research, 37(12), 1590-1597.

Galloway, J. N., Hiram Levy, I. I., \& Kasibhatla, P. S. (1994). Year 2020: Consequences of population growth and development on deposition of oxidized nitrogen. Ambio, 120-123.

Holton, I., Glass, J., \& Price, A. D. (2010). Managing for sustainability: findings from four company case studies in the UK precast concrete industry. Journal of Cleaner Production, 18(2), 152-160.

Hyde, J. (2002). USB Design by Example: A Practical Guide to Building I/O Devices with CD-ROM. Intel Press.

Liquid Stone: New Architecture in Concrete, National Building Museum, Washington, D.C., 2004.

Malhotra, V M. Role of Supplementary Cementing Materials and Superplasticizers in Reducing Greenhouse Gas Emissions, Proceedings of ICFRC International Conference on Fiber Composites, High-Performance Concrete, and Smart Materials, Chennai, India, January 2004, pp. 489-499. 
McCaffery, R. (2002). Climate change and the cement industry. Global cement and lime magazine (environmental special issue), 15-19.

McDonough, W Partners. The Hannover Principles: Design for Sustainability, EXPO 2000, The World's Fair, Hannover, Germany, 1992.

McKay, D T. Sustainability in the Corps of Engineers, a paper presented at the Technical Session Sponsored by the ACI Board Advisory Committee on Sustainable Developments, Washington, D. C., March 2004.

Mehta, P K. Greening of the Concrete Industry for Sustainable Development, ACI Concrete International, Vol. 24, No. 7, 2002, pp. 23-28.

Mehta, P. K. (2004, May). High-performance, high-volume fly ash concrete for sustainable development. In Proceedings of the international workshop on sustainable development and concrete technology (pp. 3-14). Ames, IA, USA: Iowa State University.

Naik, T R, and Kraus, R N. The Role of Flowable Slurry in Sustainable Developments in Civil Engineering, Proceedings of the ASCE Conference on Materials and Construction - Exploring the Connection, Cincinnati, Ohio, 1999, 9 pages.

Naik, T R, Kraus, R N, Ramme, B W, and Siddque, R. Long-Term Performance of High-Volume Fly Ash Concrete Pavements, ACI Materials Journal, Vol. 100, No. 2, 2003, pp. 150-155.

Naik, T. R. (2007). Sustainability of the cement and concrete industries. In Sustainable Construction Materials and Technologies, Taylor \& Francis Group.

Naik, T. R. (2008). Sustainability of concrete construction. Practice Periodical on Structural Design and Construction, 13(2), 98-103.

Sakai, K., \& Noguchi, T. (2012). The sustainable use of concrete. CRC press.

Santero, N., Loijos, A., Akbarian, M., Ochsendorf, J., Hub, C. S., \& Room, M. I. T. (2011). Methods, impacts, and opportunities in the concrete pavement life cycle. Report for Concrete Sustainability Hub.

United States House Resolution 394, March 2004.

W. McDonough, The Hannover Principles. Design for Sustainability, 2000.

WORRELL, E, AND GALTISKY, C. Energy Efficiency Improvement and Cost Saving Opportunities for Cement Making, Lawrence Berkeley National Laboratory, Publication No. LBNL-54036, January 2004, 62 pages.

WU, Z. Development of High-Performance Blended Cement, PhD thesis, T. R. Naik advisor, Department of Civil Engineering and Mechanics, College of Engineering and Applied Science, 2000, 177 pages.

Z.-C. Zhao (2011) Impacts of urbanization on climate change, 10,000 Scientific Difficult Problems: Earth Science (in Chinese), 10,000 scientific difficult problems Earth Science Committee Eds, 2011, Science Press, pp. 843-846. 